\title{
The effect of elevational gradient on alpine gingers (Roscoea alpina and $R$. purpurea) in the Himalayas
}

\author{
Babu Ram Paudel ${ }^{\text {Corresp., } 1,2,3}$, Adrian G Dyer ${ }^{4}$, Jair E Garcia ${ }^{4}$, Mani Shrestha ${ }^{4}$ \\ ${ }^{1}$ Yunnan Key Laboratory of Plant Reproductive Adaption and Evolutionary Ecology, Yunnan University, Kunming, Yunnan, China \\ 2 Laboratory of Ecology and Evolutionary Biology, State Key Laboratory for Conservation and Utilization of Bio-Resources in Yunnan, Yunnan University, \\ Kunming, Yunnan, China \\ 3 Department of Botany, Prithvi Narayan Campus, Tribhuvan University, Pokhara, Gandaki, Nepal \\ 4 School of Media and Communication, RMIT University, Melbourne, Victoria, Australia \\ Corresponding Author: Babu Ram Paudel \\ Email address: babu@xtbg.ac.cn
}

There is currently enormous interest in how morphological and physiological responses of herbaceous plants may be affected by changing elevational gradient. Mountain regions provide an excellent opportunity to understand how closely related species may adapt to the conditions that rapidly change with elevation. We investigated the morphological and physiological responses of two Himalayan alpine gingers (Roscoea alpina and $R$. purpurea) along two different vertical transects of $400 \mathrm{~m}, R$. purpurea between $2174-2574 \mathrm{~m}$ a.s.I and $R$. alpina between 2675-3079 $\mathrm{m}$ a.s.l. We measured the variables of plant height, leaf length, leaf area, specific leaf area, and stomata density at five plots, along the vertical transect at an elevational gap of ca. $100 \mathrm{~m}$. Results revealed that with increased elevation plant height, and leaf area decreased while stomata density increased, whereas changes in specific leaf area, were not correlated with the elevation. Our results reveal that these alpine gingers undergo local adaptation by modifying their plant height, leaf area and stomata density in response to the varying selection pressure associated with the elevational gradient. Thus, the findings of this research provide valuable information on how a narrow range of elevational gradient affects the herbaceous plants at the alpine habitat of the Himalayas. 


\section{RESEARCH ARTICLE}

2 The effect of elevational gradient affect on alpine gingers (Roscoea alpina and $R$.

3 purpurea) in the Himalayas

4

5 Babu Ram Paudel 1,2,3*, Adrian G. Dyer ${ }^{4}$, Jair E. Garcia ${ }^{4}$, and Mani Shrestha ${ }^{4}$

6 'Yunnan Key Laboratory of Plant Reproductive Adaption and Evolutionary Ecology, Yunnan 7 University, Kunming, China.

$8 \quad{ }^{2}$ Laboratory of Ecology and Evolutionary Biology, State Key Laboratory for Conservation and 9 Utilization of Bio-Resources in Yunnan, Yunnan University, Kunming,650091, Yunnan, P.R. 10 China

$11{ }^{3}$ Department of Botany, Prithvi Narayan Campus, Tribhuvan University, Pokhara, Nepal

$12{ }^{4}$ School of Media and Communication, RMIT University, Melbourne, Victoria 3001, Australia

13 *For correspondence: brp2033@gmail.com 
26

27 There is currently enormous interest in how morphological and physiological responses of

28

29

\section{Abstract}

herbaceous plants may be affected by changing elevational gradient. Mountain regions provide an excellent opportunity to understand how closely related species may adapt to the conditions that rapidly change with elevation. We investigated the morphological and physiological responses of two Himalayan alpine gingers (Roscoea alpina and R. purpurea) along two different vertical transects of $400 \mathrm{~m}$, R. purpurea between 2174- $2574 \mathrm{~m}$ a.s.1 and $R$. alpina between 2675-3079 $\mathrm{m}$ a.s.1. We measured the variables of plant height, leaf length, leaf area, specific leaf area, and stomata density at five plots, along the vertical transect at an elevational gap of ca. $100 \mathrm{~m}$. Results revealed that with increased elevation plant height, and leaf area decreased while stomata density increased, whereas changes in specific leaf area, were not correlated with the elevation. Our results reveal that these alpine gingers undergo local adaptation by modifying their plant height, leaf area and stomata density in response to the varying selection pressure associated with the elevational gradient. Thus, the findings of this research provide valuable information on how a narrow range of elevational gradient affects the herbaceous plants at the alpine habitat of the Himalayas. 


\section{Introduction}

48

49

The elevational gradient is one of the key environmental factors that affect growth, morphology and physiology of plants (Cordell et al., 1998; Hultine \& Marshall, 2000; Qiang et al., 2003). The elevational gradient in alpine regions provides a sharp environmental change across relatively short spatial distances because small changes in elevation can lead to a large shift in temperature, humidity, exposure, and concentration of atmospheric gases (Hovenden \& Vander Schoor, 2004). Thus, alpine environments can provide useful natural avenues to investigate the response of plants to a suite of climatic conditions that are representative of the broader latitudinal range (Montesinos-Navarro et al., 2011). With the increase in elevation, there is typically an increase in both precipitation and light intensity including changes in distributions of short wavelength UV-A (315-400 nm) and UV-B (280-315 nm) radiation (Diffey, 1991; Rozema et al., 1997) whilst temperature and concentration of carbon dioxide and oxygen decrease (Friend \& Woodward, 1990). These environmental variations may potentially alter the morphology and physiology of plants to endure the different stresses linked with changing elevation (Hovenden \& Brodribb, 2000; Körner, 2007).

The alpine environment is potentially affected by climate change associated with global warming, and thus alpine plants may face rapidly changing environmental conditions that likely impose different stress levels on plants (Beniston, 2003; Byars, Papst \& Hoffmann, 2007). Thus, based on the adaptative plasticity, the plant species exhibit local adaptation by altering the morphological and/or physiological traits over the range of elevational gradient (Hirano, Sakaguchi \& Takahashi, 2017). For example, local adaptations of plants in response to variable 
68 climatic conditions at different elevations may result in variation of plant height and leaf length

69 (Wang \& Gao, 2004). Variation in carbon assimilation, energy balance and water relations along

70 the elevational gradient could result in variation of leaf morphological and physiological traits

71 such as leaf area, specific leaf area (SLA) and stomata density (Ackerly et al., 2002). Therefore,

72 the study of the variation in the growth forms, morphology and physiology of a plant species along

73 an elevational gradient could provide valuable insights on how plants may respond to

74 environmental stress imposed by rapid changes in climatic conditions (Premoli \& Brewer, 2007;

75 Körner, 2007; Bresson et al., 2011).

76 Although several previous studies have documented the effects of elevational gradient on

77 the growth, morphology and physiology of the plants, most of the studies are focused on tree

78 species (Cordell et al., 1998; Hultine \& Marshall, 2000; Li et al., 2008). Recently a few studies

79 have been conducted to understand how the elevational gradients affect the herbaceous plants

80 (Gonzalo-Turpin \& Hazard, 2009; Scheepens, Frei \& Stöcklin, 2010; Hulshof et al., 2013; Bastida,

81 Rey \& Alcántara, 2015; Takahashi \& Matsuki, 2017; Kiełtyk, 2018). These studies particularly

82 focused on the variation of a specific trait, such as vegetative trait, reproductive trait or leaf trait.

83 Currently however, there is a lack of empirical evidence on the adaptative potential of herbaceous

84 plants along the elevational gradient in steep environments such as the Himalayas. As the alpine

85 ecosystem in the Himalayas is likely to experience the adverse effects of the changing climate

86 associated with global warming and anthropogenic disturbances (Beniston, 2003; Byars, Papst \&

87 Hoffmann, 2007), understanding the performance of herbaceous plants along the elevational

88 gradient provides important insights for the enhanced prediction of the response of herbaceous

89 plants under altered climatic conditions. 

and the only alpine member of the predominately-tropical family Zingiberaceae (Cowley, 1982, 2007). The genus is distributed between the elevations of ca 1500 to $4500 \mathrm{~m}$ a.s.1 (Cowley, 2007), thus serving as a key model for how herbaceous plants respond to the potentially stressful environmental conditions associated with increasing elevation. All Roscoea species are small herbs with annual leafy shoots produced from a reduced erect rhizome (Cowley, 1982, 2007). Among the Roscoea species, $R$. alpina Royle and R. purpurea Smith are widely distributed in the Himalayan Mountains from Kashmir (Pakistan) in the west through Nepal, India, Bhutan and Tibet. As these two Roscoea species are widely distributed from low to high elevations, characterization of the variation in morphological and physiological traits along the elevational gradient will help to understand how these alpine gingers respond to changes in climatic conditions associated with elevation. In this study, we explore the changes in the morphological (plant height and leaf length) and physiological variables (leaf area, SLA and stomata density) of these alpine gingers along the well-defined elevational gradient in the Himalayan mountain range.

\section{Materials and Methods}

\section{Study species}

The two widespread Roscoea species used in this study were $R$. alpina and R. purpurea (Fig. 1). Roscoea alpina is a common species with a wide distribution between the elevations 2130-4270 $\mathrm{m}$ a.s.1 in the Himalayan range from Kashmir (Pakistan) in the west through Bhutan in the east. The annual pseudostem may grow up to $12-20 \mathrm{~cm}$ high and presents flowers from the end of May to mid-August (Cowley, 2007). It has 2-3 obtuse sheathing leaves. Leaves are usually 1-2 in number and underdeveloped; occasionally the plant may bear up to four well-developed leaves. Leaves are linear, broadly elliptic or lanceolate. Only the first leaf is slightly auriculate and widest 
113 at the base while rest of the leaves are widest at the middle, with $17-25 \mathrm{~cm}$ in length. Leaves are

114 usually glabrous but young leaves are occasionally hairy at acute apex. Inflorescences are without

115 exserted peduncle. Flowers are deep purple to white in appearance for a human observer (Fig. 1).

116 A single plant can develop up to five flowers, however only one flower blooms at a time. Obtuse

117 to almost truncate bracts are shorter than the ovary. The calyx is much longer than the bract and

118 bluntly bi-dentate. A long corolla tube is exserted from the calyx (Cowley, 2007).

119 Roscoea purpurea is also a widespread member of the Himalayan Roscoea, distributed

120 between the elevations 1520-3100 m a.s.l. from Himachal Pradesh (India) in the west through

121 Assam/Bhutan in the east. The annual erect pseudostem is most variable in habit and form and

122 may grow up to $25-38 \mathrm{~cm}$ high, bearing 0-2 obtuse to truncate sheathing leaves. Leaves are usually

123 4-8 in number, lanceolate to oblong-ovate and 14-20 cm long with acuminate and sometimes with

124 ciliated apex. Lower leaves are slightly auriculate at the base. The plant flowers from the end of

125 June to early September (Cowley, 2007). The inflorescence is enclosed in upper leaf sheaths with 126 only the upper part of bracts and flowers visible. Flowers are light purple or white with purple

127 markings. Usually, 1-2 flowers open at a time. Bracts longer than calyx with acute apex which is

128 pale green. The sharply bi-dentate and apiculate calyx is usually pale green and sometimes marked

129 with pink. The corolla tube has a mauve or white colouration and is hardly exserted from the calyx

130 (Cowley, 2007).

131 Study sites

132 The research was conducted along an elevational gradient at two sites, Daman and 133 Ghorepani, Central Nepal (Fig. 2). Daman is located in Makawanpur district and forms a part of 134 the Mahabharat mountain range (mountains lower than the Himalayas). This site lies about $70 \mathrm{~km}$ 135 south-west of Kathmandu and is midway between Kathmandu and Hetauda. The vegetation type 
136 of this site typically comprises a mixed forest of Pinus (Pinus roxburghii), Rhododendron ( $R$.

137 arboreuum, $R$. campanualatum) and Quercus (Q. semecarpifolia, Q. lanata). The site experiences

138 cool temperate to subalpine climate with warm summers and cold winters that typically incur mild

139 to heavy snowfall from November to February (Pers. Obs. BRP). Ghorepani, located in Myagdi

140 district, is about $270 \mathrm{~km}$ west of Kathmandu. The vegetation type of this site comprises a mixed

141 forest of Pinus (P. wallichiana), Abies (A. spectabilis) and Rhododendron (R. arboretum, R.

142 barbatum, $R$ campanulatum, $R$ antohopogon at upper limit). The site has a subalpine climate and

143 cool weather throughout the year, and heavy snowfall from November to February (Pers. Obs.

144 BRP). The geographical coordinates and the elevations of the study sites are presented in Table 1451.

146 Measurement of traits

147 The field sampling was conducted from May to August 2014 and repeated the sampling again in 2017 (May to August). Five sampling plots were selected along a vertical transect from 2174 to $2574 \mathrm{~m}$ a.s.1. for $R$. purpurea and from 2675 to $3079 \mathrm{~m}$ a.s.l. for $R$. alpina. The sampling was done in a counterbalanced random fashion such that two adjacent sampling plots were at an elevation gap of ca $100 \mathrm{~m}$. Plant height and leaf length were measured to examine the morphological variables. Physiological variables included leaf area, specific leaf area (SLA) and stomata density. At each sampling plot, a horizontal transect of $100 \mathrm{~m}$ length was laid down and twenty plants were randomly selected along the horizontal transect in such a way that the distance plant height (the distance from the ground to the topmost part of the stem). The largest leaf of 157 every sampled plant was removed and leaf length was measured with a ruler. We used a graph 158 paper to trace and quantify the area of each leaf, enabling robust repeatable measurements in 
159 remote locations. Specifically, two alternative methods were used to measure the area of the leaf. 160 In 2014, the area of the leaf was measured after wet storage, while in 2017 the area was measured 161 on the freshly plucked leaf. To prevent the leaves from possible shrinkage during wet storage, the 162 leaves were first flattened if necessary and carefully placed in between the folds of a paper. 163 Resulting samples were then placed in a sample box to avoid the external light and heat sources. 164 For both respective leaf collection methods, the leaf (either wet stored or freshly plucked) was 165 placed on a graph paper, its outline was sketched and the number of squares enclosed within the 166 leaf-outline were counted. Complete and greater than half squares were scored, whilst squares less 167 than half a square were excluded. The measurements were repeated several times for each leaf to enable a robust field measurement of leaf area. Twenty leaves at each sampling plot were measured to assess variability. The area of leaf as measured by two alternative methods did not differ significantly ( $t$ test, $\mathrm{P}>0.05$ ), thus data generated from the freshly removed leaf were used for

171 further analysis. All collected leaves were gently pressed between the folds of an absorbent paper 172 for five days to flatten the leaf surface and to absorb any excess moisture. The pressed leaves were subsequently oven dried at the university laboratory for 48 hours at $70^{\circ} \mathrm{C}$. Dry leaf weight was measured using a digital electronic balance (Fameway International (HK) Limited; accuracy 0.001g). Specific leaf area (SLA) of a leaf was calculated as the ratio of the area of a fresh leaf and 176 its dry weight and expressed in $\mathrm{cm}^{2} / \mathrm{g}$.

To determine the stomatal count, transparent nail polish was applied on the middle dorsal surface of a fresh leaf. After a few minutes, when nail polish had dried, a thin layer was peeled from the middle dorsal surface of a leaf. The peeled layers were separately preserved in a $10 \%$ glycerine solution for about 72 hours. In the laboratory, the temporary slide of each layer was

181 prepared using safranin as a staining agent. The stained layers were individually mounted on 
182 microscope slides, and all stomata observed under a 10-x magnification microscopic field were 183 counted. The stomata counts were repeated at three different microscopic fields to ensure the exact 184 measurement of the stomata density. Area of the microscopic field was calculated using the 185 formula $A=\pi r^{2}$ where $r$ is the radius of microscopic field and density of stomata was calculated as 186 the number of stomata under a microscopic field divided by the area of the microscopic field. The 187 stomata density was expressed in terms of number per square millimetre.

188

189

190

191

192

193

194

195

196

197

198

199

200

201

202

203

204

\section{Statistical Analyses}

An independent sample $t$ test was used to test the variation in measured traits between the years. Data from each of the measured morphological variables were summarized as Q-Q plots and tested for normality. Exploratory data analyses revealed that some of the response variables were not normally distributed and were better described by a Gamma distribution as most data consisted of positive values larger than zero (Zuur, Hilbe \& Ieno, 2013). Consequently, nonparametric correlation analyses were performed among the five different traits measured for each species implementing Kendall's tau statistic $(\tau)$. This coefficient was chosen as it has a known standard error and provides a better estimate with low sample size. After the exploratory analyses, generalised linear regression models (GLM) were applied to test for the potential effects of elevation on the different traits measured for each species. For the five regression models, elevation was used as a predictor and it was assumed that the response variable followed a Gamma distribution. Link function for each model was selected based on a comparison of AIC scores obtained after fitting models implementing different link functions (Zuur, Hilbe \& Ieno, 2013). Regression analyses were performed using the routine glm available as part of the base distribution of the $\mathrm{R}$ language and environment for statistical computing (version 3.3.1) (R Core Team, 2015). 


\section{Correlation analyses}

207

208

209

210

211

212

213

214

215

216

217

218

219

220

221

222

223

224

Our results indicated that all the measured variables did not differ significantly between years ( $\mathrm{P}>0.05)$, thus only 2017 data were used for further analyses. For $R$. purpurea, there was a significant correlation between stomata density and the variables of leaf area $(\mathrm{P}<0.001)$ and specific leaf area (SLA) $(\mathrm{P}=0.020)$ (Fig. 3). In R. alpina, leaf length was correlated with all remaining variables (Fig. 4). Consequently, we separately performed the regression analyses for the two species for each of the measured response variables.

\section{Variations of traits with elevation}

Leaf length of $R$. alpina and plant height significantly decreased with increasing elevation ( $\mathrm{P}=0.001$ for leaf length and $\mathrm{P}=0.017$ for plant height). The same trend was observed for leaf area $(\mathrm{P}<0.001)$, while stomata density increased with elevation $(\mathrm{P}=0.005)$. SLA values for this species were not significantly correlated with elevation $(\mathrm{P}=0.114)$ (Fig. 5).

Plant height and leaf area significantly decreased, while stomata density increased, with increasing elevation in $R$. purpurea $(\mathrm{P}=0.044, \mathrm{P}=0.001$ and, $\mathrm{P}=0.002$ for plant height, leaf area and stomata density respectively). However, we did not find a significant relationship of elevation either with leaf length $(\mathrm{P}=0.471)$ or with SLA $(\mathrm{P}=0.555)$ (Fig. 5). Details on the regression analysis including coefficients and associated $95 \%$ confidence intervals are provided in Table 2 and Table 3. 
In the current study, we found a significant decrease in plant height of both species of

228

229

230

231

232

233

234

235

236

237

238

239

240

241

242

243

244

Roscoea (R. alpina and R. purpurea) with increased elevation. Reduction of plant height in these alpine gingers with increased elevation is consistent with several previous findings reported for tree species (Körner, 1998; Cordell et al., 1998; Kronfus \& Havranek, 1999; Paulsen, Weber \& Korner, 2000; Kogami et al., 2001; Li, Yang \& Kräuchi, 2003; Shi et al., 2006) and herbaceous species (Takahashi \& Matsuki, 2017; Kiełtyk, 2018). Similarly, a decrease of leaf length of $R$. alpina with the increased elevation in the current study is consistent with the previous findings (Hansen-Bristow, 1986; Schoettle, 1990; Kajimoto, 1993; Kao \& Chang, 2001; Kiełtyk, 2018). Based on the present result, we conclude that the elevational gradient has a significant effect on the growth form of these alpine gingers. At the lower elevation, environmental conditions are likely to be more favourable for optimum plant growth. The reduction of plant height and leaf length of these two alpine gingers with increasing elevation reflects the morphological adaptation to increased environmental stresses such as low concentration of carbon dioxide, decreased temperature, higher solar radiation and/or low water availability (Wang \& Gao, 2004; Davis, Shaw \& Etterson, 2005; Guerin, Wen \& Lowe, 2012). The observed relatively smaller plants with shorter leaf characteristics of these gingers at higher elevation thus may reflect local adaptation at a higher altitude to enable reduction of transpiration and maintain efficient utilization of water (Ackerly et al., 2002; Royer et al., 2008; Peppe et al., 2011; Guerin, Wen \& Lowe, 2012). 
Leaf traits variation with elevation:

Our findings revealed that variation in leaf area showed a significant but negative correlation with elevation, while the correlation between SLA and elevation was non-significant.

249 Consistent with our result, Kouwenberg, Kurschner and McElwain (2007) found a decreasing 250 trend in the leaf area of Quercus kelloggii with increasing elevation. Our result on the variation of leaf characters (leaf area and SLA) with the elevation is partially consistent with the previous findings reported by Hultine and Marshall (2000); Scheepens, Frei and Stöcklin (2010); Hulshof et al., (2013); Bastida, Rey and Alcántara, (2015), while the findings of Gonzalo-Turpin and Hazard (2009) indicate a different effect. Previous studies have suggested that the environment at higher elevations is characterized by higher solar radiation, lower water availability and lower stomatal conductance (Parkhurst \& Loucks, 1972; Givnish \& Vermeij, 1976; Ackerly et al., 2002). Under such potentially stressful environmental conditions, small leaf size provides optimum adaptation to the plants by reducing boundary layer resistance and maintaining favorable leaf temperature and high photosynthetic water use efficiency (Renzhong et al., 2001). Thus, decreased leaf area of these alpine gingers with increased elevation may reflect an adaptation for the increased environmental stress and may be favourable to reduce water loss and maintain efficient use of absorbed water (Renzhong et al., 2001). In addition, some authors have implicated increasing UVB radiation levels as having a damaging effect on certain plant structures (Jansen, Gaba \& Greenberg, 1998; Rozema, Aerts \& Cornelissen, 2002); and there is some evidence of this affecting plant growth in some lowland terrestrial species (Rozema, Aerts \& Cornelissen, 2002). These topics may be of high value to explore in alpine environments where there are likely large changes in UV levels. SLA is closely associated with leaf thickness, which mediates the trade-off 
268 between light capture, water loss and diffusion of carbon dioxide (Oberle \& Schaal, 2011). Higher

269 SLA leaves are thicker and contain more photosynthetic enzymes and there is more demand for

270 carbon dioxide per unit area. Thus, stomata density increases to supply the higher demand for

271 carbon dioxide. Consequently, the increase in SLA may be an advantage for carbon dioxide uptake.

272 Non-linear change of SLA of both species along the elevational gradient may indicate that

273 environmental factors associated with altitude alone cannot regulate the trade -off between light

274 capture, water loss and diffusion of carbon dioxide in these alpine gingers. The smallest SLA of

$275 R$. alpina at $2674 \mathrm{~m}$ a.s.1 and $R$. purpurea at $2374 \mathrm{~m}$ a.s.1 may indicate limited carbon gain and

276 supply due to poor availability of resources and may be associated with the least productive zone

277 of these species where retention of captured resources and protection from desiccation is of high

278 priority (Wilson, Thompson \& Hodgson, 1999).

Variation in Stomata density with Elevation

We found a significant increase in stomata density of both species ( $R$. alpina and $R$.

281

282

283

284

285

286

287

288

289

290 purpurea) with increased elevation. Many authors have made comprehensive efforts to relate the variation in stomata density along elevation gradients and have obtained different results. Consistent to our current results, Körner and Cochrane (1985); Friend and Woodward (1990); Hovenden and Brodribb (2000); and Kouwenberg, Kurschner and McElwain (2007) have found that stomata density increased linearly with elevation. Li et al. (2006) found that stomata density of Quercus aquifolioides increased linearly up to the height of $2800 \mathrm{~m}$ a.s.1., whilst above that height, it decreased linearly. Schoettle and Rochelle (2000) found that the stomata density of Pinus flexilis decreased linearly with altitude whilst Woodward (1986) did not observe any significant change in stomata density of Vaccinium myrtillis considering altitudes from 200 to $1100 \mathrm{~m}$ asl. The significant increase in stomata density with increasing elevation in our findings may be associated 
291 with lower availability of carbon dioxide, higher UV-B and long wave radiation, all reducing

292 photosynthetic efficiency by decreasing stomatal absorption and conductance (Kouwenberg, 293 Kurschner \& McElwain, 2007; Körner, 2007). To adapt to such a harsh environmental conditions 294 and maintain vitalities, stomata density of these gingers may have increased. The increase in 295 stomata density provides compensation against the reduced stomatal conductance and carbon 296 dioxide partial pressure to maintain photosynthetic efficiency (Kao \& Chang, 2001; Kouwenberg, 297 Kurschner \& McElwain, 2007; Körner, 2007).

Our results indicate two major patterns in the vegetative traits of these alpine gingers with 299 increased elevation: a significant decrease of leaf area and a significant increase of stomata density. These variations provide compensation to cope with the change in the concentration of atmospheric carbon dioxide, temperature, humidity and light at higher altitudes (Van de Water, Leavitt \& Betancourt, 1994; Hultine \& Marshall, 2000; Qiang et al., 2003). A non-significant correlation between SLA and stomata density may suggest that leaf thickness have little role in regulating the carbon dioxide uptake and transpiration in these two alpine gingers. A negative correlation of stomata density with leaf area has previously indicated that with the increase of stomata density at a higher elevation, narrowing of leaves may reduce excess transpiration (Herms \& Mattson, 1992; Etterson \& Shaw, 2001). The closely correlated variation in these two traits thus maintains a likely trade-off between photosynthesis and transpiration and provides local adaptation to the specific conditions, at different elevations.

Growth, morphology and physiology of $R$. alpina and $R$. purpurea were found to have a

312 significant association with altitude. These alpine gingers exhibit optimum growth at their 313 respective lowermost distribution range, and their growth response retards with increasing 
314 elevation. Based on the present result, it can be concluded that these alpine gingers favour shorter

315 height, smaller leaf and higher stomata density at a higher elevation to adapt with the stressful

316 factors associated with the change in elevational gradients. Variation in those traits at different

317 elevations may reflect the response to the combined selection pressure of different abiotic and

318 biotic factors that may generate different micro-environmental conditions at the respective

319 elevation. Decreased growth forms and leaf area of these alpine gingers at a higher altitude may

320 indicate a selection response to reduce water loss from the plant body during transpiration while

321 increased stomata density may indicate the adaptation to cope with the decreased concentration of

322 carbon dioxide. The closely correlated modification of these traits at different elevations may have

323 played a significant role in providing local adaptation to these alpine gingers.

\section{Acknowledgements}

We are thankful to the Department of Plant Resources, Thapathali, Kathmandu for

providing research permission. We thank Mr Kul Prasad Lamichhane, Kapil Paudel, and Dipesh

Baral for assistance in the field. We thank Dr Subodh Adhikari for the constructive comments on

the earlier version of the manuscript. We thank Dr Lalina Muir for proof reading the manuscript.

We also thank Editor Dr Gabriele Casazza, reviewer Dr Marco Porceddu and an anonymous reviewer for their constructive suggestion.

\section{References}

333
Ackerly DD, Knight CA, Weiss SB, Barton K, Starmer KP. 2002. Leaf size, specific leaf area and microhabitat distribution of chaparral woody plants: contrasting patterns in species level and community level analyses. Oecologia 130:449-457. DOI: $10.1007 / \mathrm{s} 004420100805$. 
337 Bastida JM, Rey PJ, Alcántara JM. 2015. Local adaptation to distinct elevational cores

338 contributes to current elevational divergence of two Aquilegia vulgaris subspecies. Journal of Plant Ecology 8:273-283. DOI: 10.1093/jpe/rtu017.

340

341

342

Beniston M. 2003. Climatic change in Mountain regions: a review of possible impacts. Climate change 59:5-31.

Bresson CC, Vitasse Y, Kremer A, Delzon S. 2011. To what extent is altitudinal variation of functional traits driven by genetic adaptation in European oak and beech? Tree physiology 31:1164-74. DOI: 10.1093/treephys/tpr084.

Byars SG, Papst W, Hoffmann A a. 2007. Local adaptation and cogradient selection in the alpine plant, Poa hiemata, along a narrow altitudinal gradient. Evolution; international journal of organic evolution 61:2925-41. DOI: 10.1111/j.1558-5646.2007.00248.x.

Cordell S, Goldstein G, Mueller-Dombois D, Webb D, Vitousek PM. 1998. Physiological and morphological variation in Metrosideros polymorpha, a dominant Hawaiian tree species, along an altitudinal gradient: the role of phenotypic plasticity. Oecologia 113:188-196. DOI: $10.1007 / \mathrm{s} 004420050367$.

Cowley EJ. 1982. A revision of Roscoea ( Zingiberaceae ). Kew Bulletin 36:747-777.

Cowley EJ. 2007. The genus Roscoea. Royal Botanic Garden Kew, UK.

Davis MB, Shaw RG, Etterson JR. 2005. Evolutionary responses to changing climate. Ecology $86: 1704-1714$.

Diffey BL. 1991. Solar ultraviolet radiation effects on biological systems. Physics in Medicine and Biology 36:299-328.

Etterson JR, Shaw RG. 2001. Constraint to aAdaptive evolution in response to global warming. Science 294:151-154. DOI: 10.1126/science.1063656. 
360 Friend AD, Woodward FI. 1990. Evolutionary and ecophysiological responses of mountain

361 plants to the growing season environment. Advances in Ecological Research 20:59-124.

362 Givnish TJ, Vermeij GJ. 1976. Sizes and shapes of liane leaves. The American naturalist $363 \quad 110: 743-778$.

364 Gonzalo-Turpin H, Hazard L. 2009. Local adaptation occurs along altitudinal gradient despite 365 the existence of gene flow in the alpine plant species Festuca eskia. Journal of Ecology 97:742-751. DOI: 10.1111/j.1365-2745.2009.01509.x.

367 368

Guerin GR, Wen H, Lowe AJ. 2012. Leaf morphology shift linked to climate change. Biology Lett.:1-5.

Hansen-Bristow K. 1986. Influence of increasing elevation on growth characteristics at timberline. Canadian Journal of Botany 64:2517-2523.

Herms DA, Mattson WJ. 1992. The dilemma of plants-to grow or defend. Q. Rev. Biol. 67:283335.

Hirano M, Sakaguchi S, Takahashi K. 2017. Phenotypic differentiation of the Solidago virgaurea complex along an elevational gradient: insights from a common garden experiment and population genetics. Ecology and Evolution 7:6949-6962. DOI: 10.1002/ece3.3252.

Hovenden MJ, Brodribb T. 2000. Altitude of origin influences stomatal conductance and therefore maximum assimilation rate in Southern Beech, Nothofagus cunninghamii. Aust. J. Plant Physiol. 27:451-456.

Hovenden MJ, Vander Schoor JK. 2004. Nature vs nurture in the leaf morphology of Southern beech, Nothofagus cunninghamii (Nothofagaceae). New phytologist 161:585-594.

Hulshof CM, Violle C, Spasojevic MJ, Mcgill B, Damschen E, Harrison S, Enquist BJ. 2013. Intra-specific and inter-specific variation in specific leaf area reveals the importance of 
383 384 385 386

387

abiotic and biotic drivers of species diversity across elevation and latitude. Journal of Vegetation Science 24:921-931. DOI: 10.1111/jvs.12041.

Hultine KR, Marshall JD. 2000. Altitude trends in conifer leaf morphology and stable carbon isotope composition. Oecologia 123:32-40. DOI: 10.1007/s004420050986.

Jansen MAK, Gaba V, Greenberg B. 1998. Higher plants and UV-B radiation: balancing damage, repair and acclimation. Trends in Plant Science 3:131-135. DOI: http://dx.doi.org/10.1016/S1360-1385(98)01215-1.

Kajimoto T. 1993. Shoot dynamics of Pinus pumila in relation to altitudinal and wind exposure gradients on the Kiso mountain range, central Japan. Tree physiology 13:41-53.

Kao WY, Chang KW. 2001. Altitudinal trends in photosynthetic rate and leaf characteristics of Miscanthus populations from central Taiwan. Aust. J. Bot. 49:509-514.

Kieltyk P. 2018. Variation of vegetative and floral traits in the alpine plant Solidago minuta: evidence for local optimum along an elevational gradient. Alpine Botany 128:47-57. DOI: $10.1007 / \mathrm{s} 00035-017-0197-7$.

Kogami H, Hanba YT, Kibe T, Terashima I, Masuzawa T. 2001. $\mathrm{CO}_{2}$ transfer conductance, leaf structure and carbon isotope composition of Polygonum cuspidatum leaves from low and high altitudes. Plant, Cell and Environment 24:529-538. DOI: 10.1046/j.13653040.2001.00696.x.

Körner C. 1998. A re-assessment of high elevation treeline positions and their explanation. Oecologia 115:445-459.

Körner C. 2007. The use of "altitude" in ecological research. Trends in ecology \& evolution 22:569-74. DOI: 10.1016/j.tree.2007.09.006.

Körner C, Cochrane PM. 1985. Stomatal responses and water relations of Eucalyptus paucitlora 
in summer along an elevational gradient. Oecologia 66:443-455.

407 Kouwenberg LLR, Kurschner WM, McElwain JC. 2007. Stomatal frequency change over

408 altitudinal gradients: prospects for paleoaltimetry. Reviews in Mineralogy and Geochemistry

$409 \quad 66: 215-241$. DOI: 10.2138/rmg.2007.66.9.

410

411

412

413

414

415

416

417

418

419

420

421

422

423

424

425

426

427

428

Kronfus H, Havranek WM. 1999. Effects of elevation and wind on the growth of Pinus cembra L . in a subalpine afforestation. Phyton(Austria) 39:99-106.

Li M-H, Xiao W-F, Shi P, Wang S-G, Zhong Y-D, Liu X-L, Wang X-D, Cai X-H, Shi Z-M. 2008. Nitrogen and carbon source-sink relationships in trees at the Himalayan treelines compared with lower elevations. Plant, cell \& environment 31:1377-1387. DOI: 10.1111/j.1365-3040.2008.01848.x.

Li MH, Yang J, Kräuchi N. 2003. Growth responses of Picea abies and Larix decidua to elevation in subalpine areas of Tyrol, Austria. Canadian Journal of Forest Research 33:653-662. DOI: 10.1139/X02-202.

Li C, Zhang X, Liu X, Luukkanen O, Berninger F. 2006. Leaf morphological and physiological responses of Quercus aquifolioides along an Altitudinal Gradient. Silva Fennica 40:5-13.

Montesinos-Navarro A, Wig J, Pico FX, Tonsor SJ. 2011. Arabidopsis thaliana populations show clinal variation in a climatic gradient associated with altitude. New phytologist 189:282-294. DOI: 10.1111/j.1469-8137.2010.03479.x.

Oberle B, Schaal BA. 2011. Responses to historical climate change identify contemporary threats to diversity in Dodecatheon. Proceedings of the National Academy of Sciences of the United States of America 108:5655-60. DOI: 10.1073/pnas.1012302108.

Parkhurst D, Loucks O. 1972. Optimal leaf size in relation to environment. Journal of Ecology 60:505-537. 
429 Paulsen J, Weber UM, Korner C. 2000. Tree growth near treeline : abrupt or gradual reduction $430 \quad$ with altitude? Arct. Antarc. Alp. Res. 32:14-20.

431 Peppe DJ, Royer DL, Cariglino B, Oliver SY, Newman S, Leight E, Enikolopov G, Fernandez-

432 Burgos M, Herrera F, Adams JM, Correa E, Currano ED, Erickson JM, Hinojosa LF,

433

434

435

436

437

438

439

440

441

442

443

444

445

446

447

448

449

450

451

Hoganson JW, Iglesias A, Jaramillo C a, Johnson KR, Jordan GJ, Kraft NJB, Lovelock EC,

Lusk CH, Niinemets U, Peñuelas J, Rapson G, Wing SL, Wright IJ. 2011. Sensitivity of leaf size and shape to climate: global patterns and paleoclimatic applications. New phytologist 190:724-39. DOI: 10.1111/j.1469-8137.2010.03615.x.

Premoli AC, Brewer CA. 2007. Environmental vs. genetically driven variation in ecophysiological traits of Nothofagus pumilio from contrasting elevations. Australian Journal of Botany 55:585. DOI: 10.1071/BT06026.

Qiang W, Xun-ling W, Chen T, Hu-yuan F, Li-zhe A, Yuan-qin H, Gang W. 2003. Variations of stomatal density and carbon isotope values of Picea crassifolia at different altitudes in the Qilian Mountains. Trees 17:258-262. DOI: 10.1007/s00468-002-0235-X.

R Core Team. 2015. R: A language and environment for statistical computing. R Foundation for Statistical Computing, Vienna, Austria. URL https://www.R-project.org/.

Renzhong W, Ripley EA, Yuangang Z, Shaoquan N. 2001. Demography of reproductive and biomass allocation of grassland and dune Leymus chinensis on the Songnen Plain, northeastern China. Journal of Arid Environments 49:289-299. DOI: 10.1006/jare.2000.0787.

Royer DL, McElwain JC, Adams JM, Wilf P. 2008. Sensitivity of leaf size and shape to climate within Acer rubrum and Quercus kelloggii. New Phytologist 179:808-817. DOI: 10.1111/j.1469-8137.2008.02496.x.

Rozema J, Aerts R, Cornelissen H (eds.). 2002. Plants and Climate Change. Vrije Universiteit, 
452

453

454

455

456

457

458

459

460

461

462

463

464

465

466

467

468

469

470

471

472

473

474

Amsterdem, The Netherlands.

Rozema J, Staaij van de J, Björn L., Caldwell M. 1997. UV-B as an environmental factor in plant life: stress and regulation. Trends in Ecology \& Evolution 12:22-28.

Scheepens JF, Frei ES, Stöcklin J. 2010. Genotypic and environmental variation in specific leaf area in a widespread alpine plant after transplantation to different altitudes. Oecologia 164:141-150. DOI: 10.1007/s00442-010-1650-0.

Schoettle AW. 1990. The interaction between leaf longevity and shoot growth and foliar biomass per shoot in Pinus contorta at two elevations. Tree physiology 7:209-214.

Schoettle AW, Rochelle SG. 2000. Morphological variation of Pinus flexilis (Pinaceae), a birddispersed pine, across a range of elevations. American Journal of Botany 87:1797-1806. DOI: $10.2307 / 2656832$.

Shi Z, Liu S, Liu X, Centritto M. 2006. Altitudinal variation in photosynthetic capacity, diffusional conductance and $13 \mathrm{C}$ of butterfly bush (Buddleja davidii) plants growing at high elevations. Physiologia Plantarum 128:722-731. DOI: 10.1111/j.13993054.2006.00805.x.

Takahashi K, Matsuki S. 2017. Morphological variations of the Solidago virgaurea L. complex along an elevational gradient on Mt Norikura, central Japan. Plant Species Biology 32:238246. DOI: $10.1111 / 1442-1984.12148$.

Wang R, Gao Q. 2004. Morphological responses of Leymus chinensis (Poaceae) to the largescale climatic gradient along the North-east China Transect (NECT). Diversity and Distributions 10:65-73. DOI: 10.1111/j.1472-4642.2004.00056.x.

Van de Water PK, Leavitt SW, Betancourt JL. 1994. Trends in stomatal density and 13C/12C ratios of Pinus flexilis needles during last Glacial-Interglacial Cycle. Science 264:239-243. 
$475 \quad$ DOI: $10.1126 /$ science.264.5156.239.

476 Wilson PJ, Thompson K, Hodgson JG. 1999. Specific leaf area and leaf dry matter content as 477 alternative predictors of plant strategies. New phytologist 143:155-162.

478 Woodward FI. 1986. Ecophysiological studies on the shrub $s$ L. taken from a wide altitudinal $479 \quad$ range. Oecologia 70:580-586.

480 Zuur AF, Hilbe JM, Ieno EN. 2013. A Beginner's Guide to GLM and GLMM with R. Highland $481 \quad$ Statistics, Newburgh, UK.

482 
Figure 1

Figure 1

Study species Roscoea purpurea (A) and R. alpina (B) in their natural habitat.
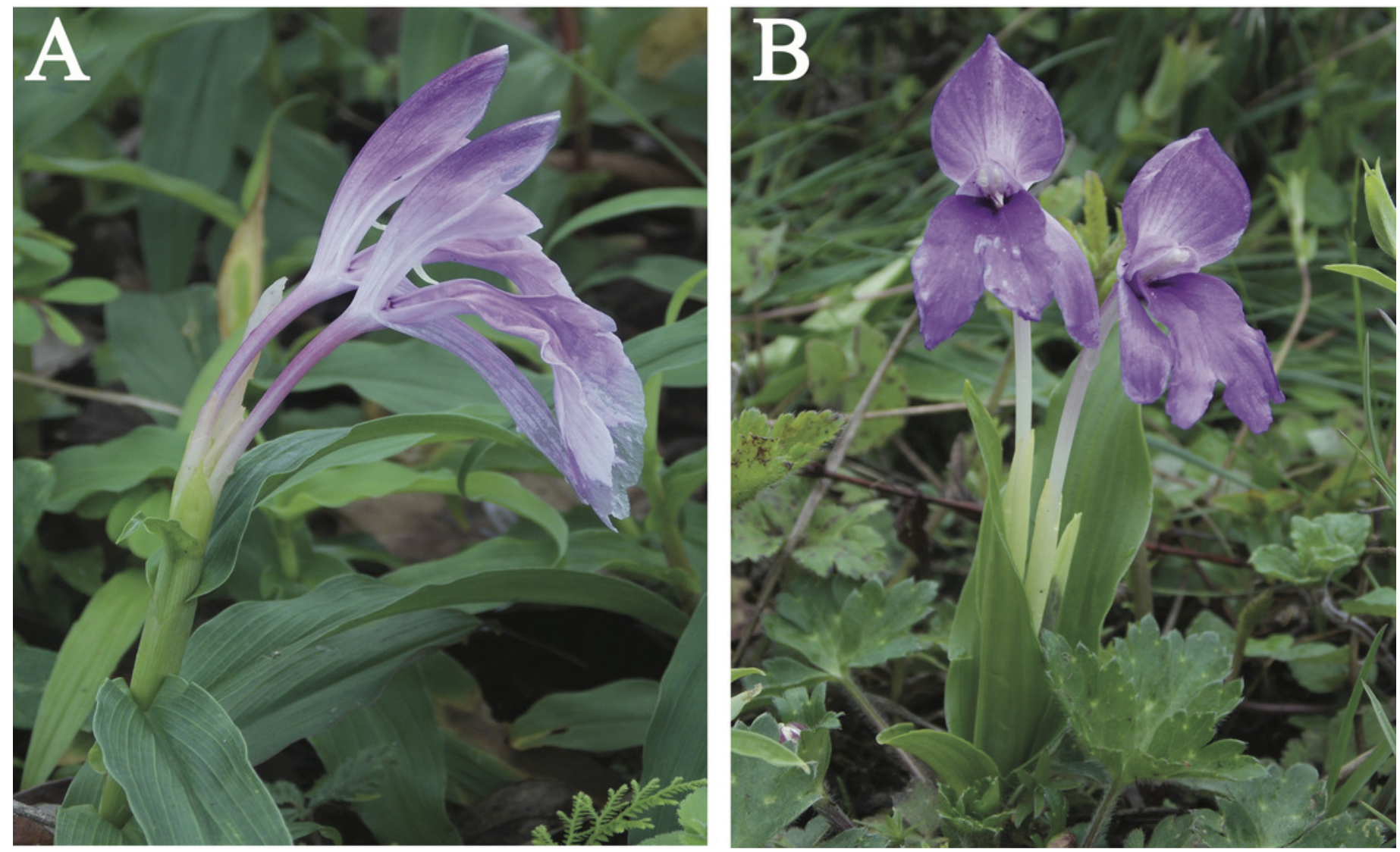


\section{Figure 2}

Figure 2

Map of the study area: Yellow hexagons represent the study site (Ghorepani ) of Roscoea alpina whereas Light-Oliventine triangles represent the study site (Daman) of R. purpurea (See Table 1 for detail). The top map represents the elevational gradient of study locations. 


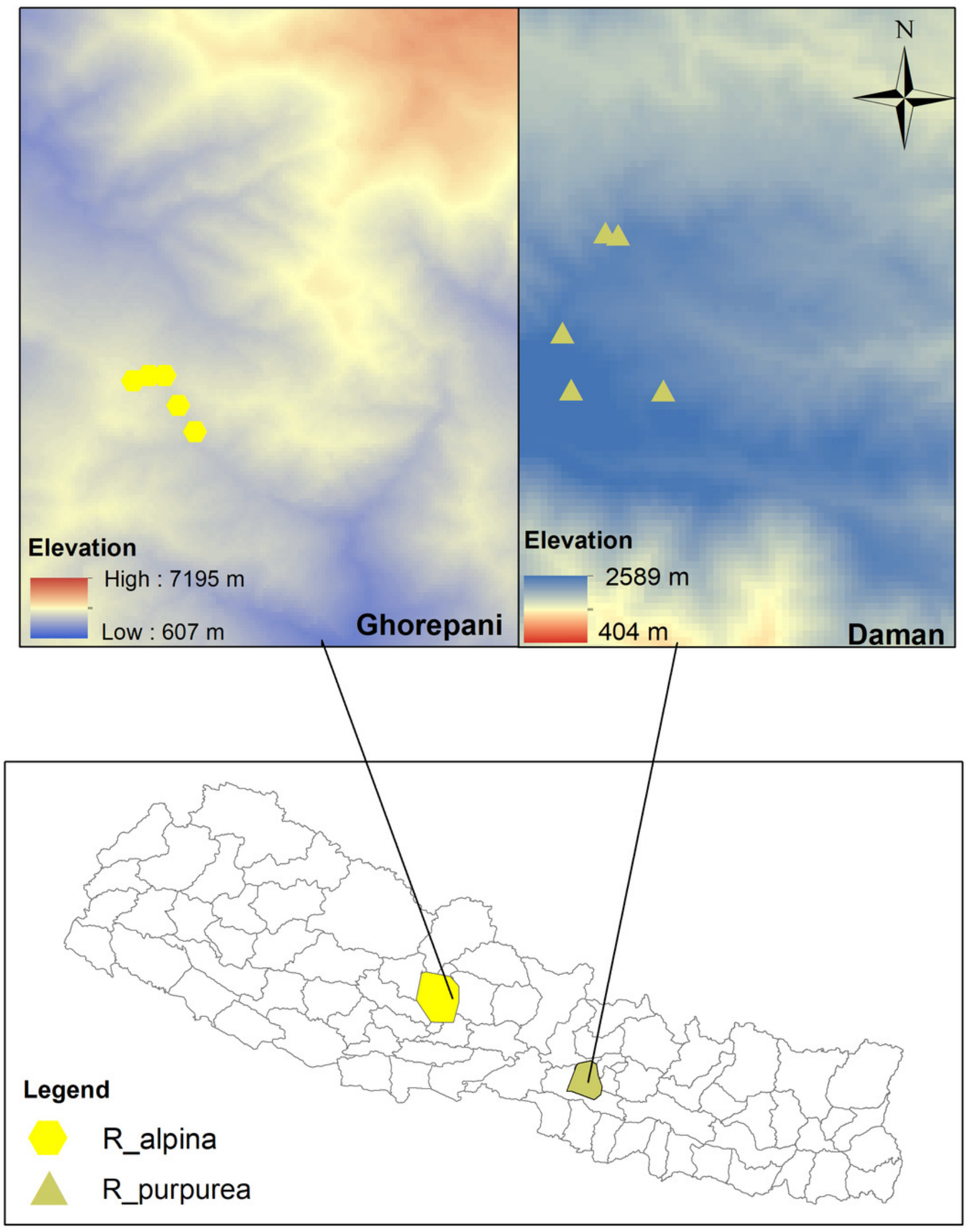


Figure 3

Figure 3

Correlations between the different traits of $R$. purpurea measured at five different elevations. 

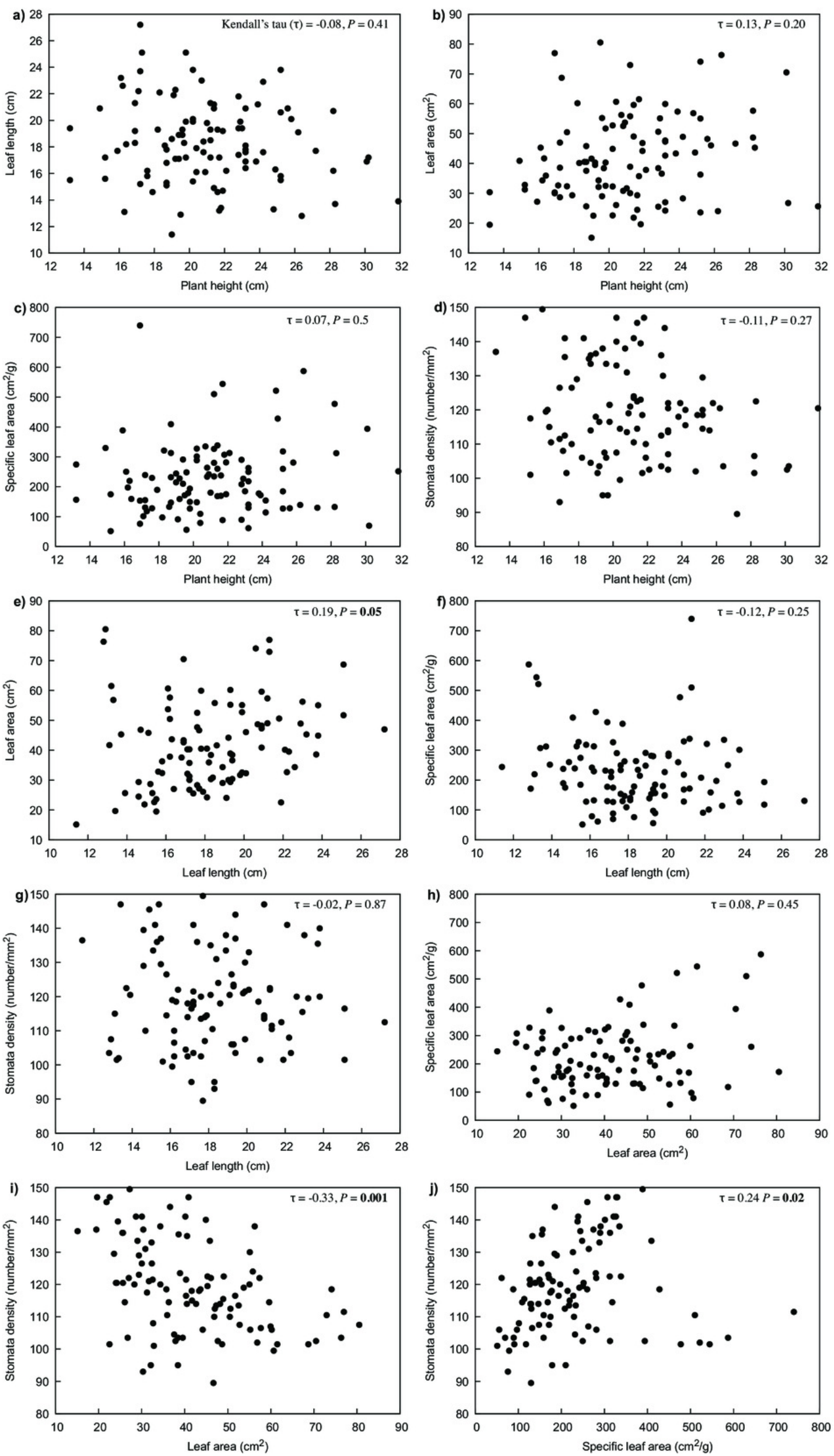

Peer] reviewing PDF | (2019:03:35929:2:0:NEW 12 Jul 2019) 


\section{Figure 4}

Figure 4

Correlations between the different traits of $R$. alpina measured at five different elevations. 

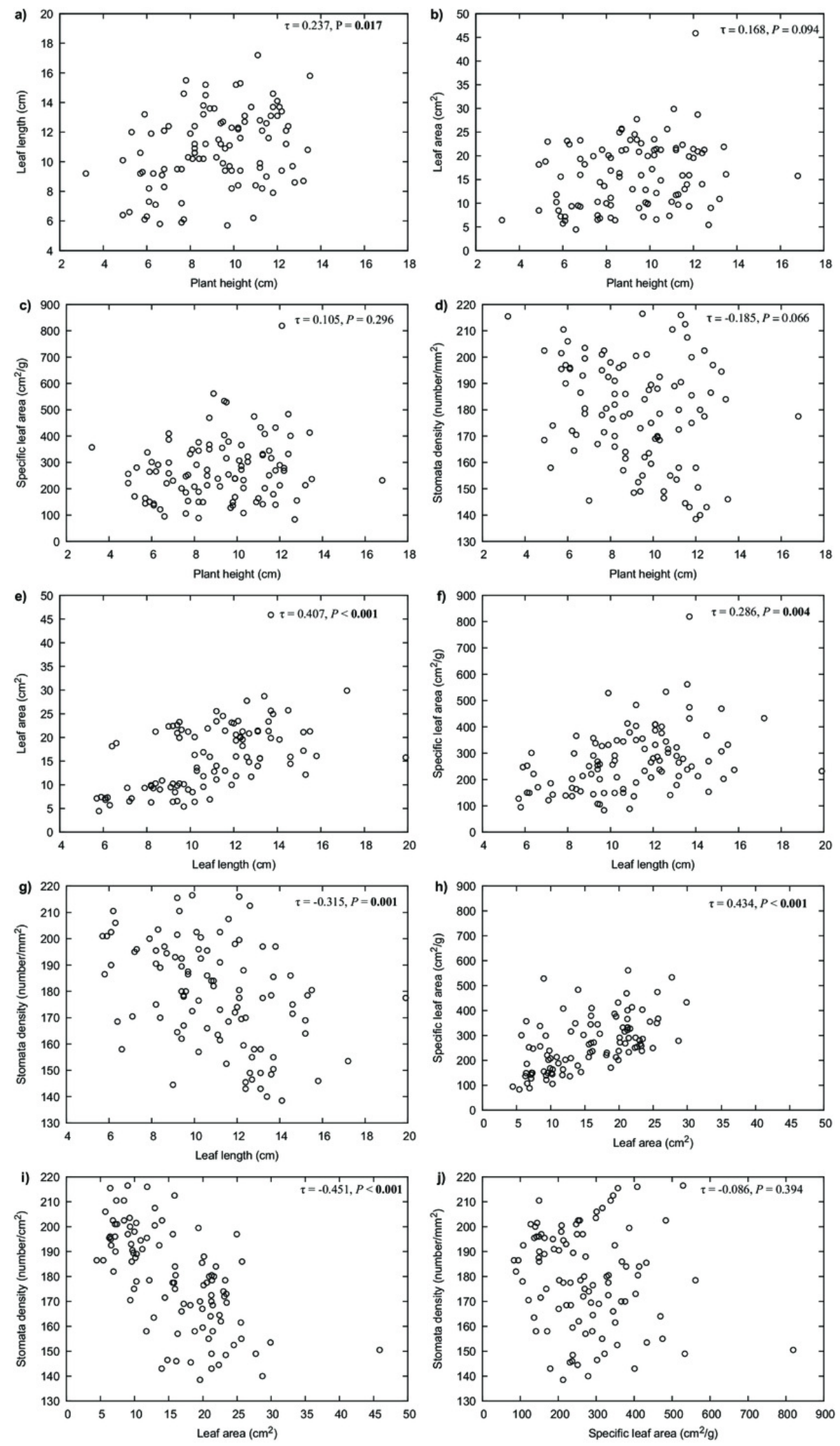


\section{Figure 5}

Figure 5

Generalised linear regression models showing the effect of elevation on plant height (fig. a), leaf length (fig. b), leaf area (fig. c), specific leaf area (fig. d) and, stomata density (fig. e) for $R$. purpurea (blue line with filled markers) and $R$. alpina (purple line with empty markers). Markers indicate the mean value of the corresponding trait at each elevation and error bars indicate standard deviation. Solid lines represent the regression function for each trait and species. A significant correlation of elevation on the value for each trait is indicated by two asterisks (**) while a non-significant correlation of elevation is indicated by "NS" above the corresponding regression line. 

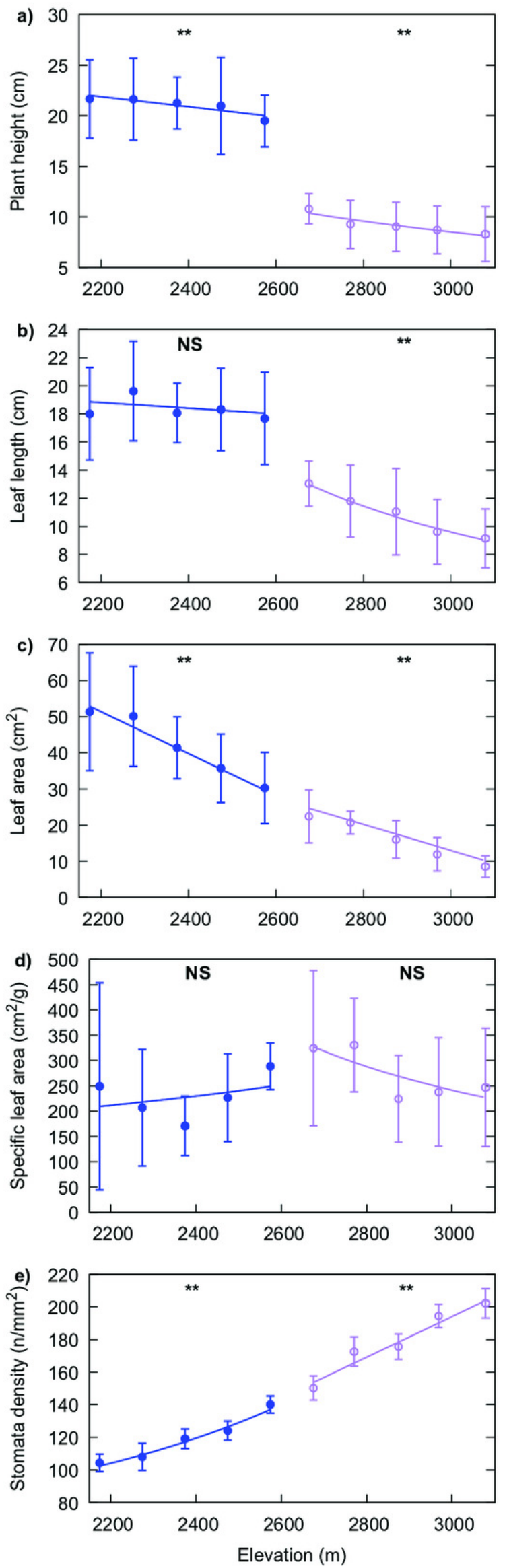

PeerJ reviewing PDF | (2019:03:35929:2:0:NEW 12 Jul 2019) 


\section{Table 1 (on next page)}

Table 1

Geographical details of the study sites. 
1 Table 1: Geographical details of study sites.

2

\begin{tabular}{llllll}
\hline \multicolumn{1}{l}{ Roscoea purpurea } & \multicolumn{3}{c}{ R. alpina } \\
\hline Latitude & Longitude & $\begin{array}{l}\text { Elevation } \\
\text { (a.s.l.) }\end{array}$ & Latitude & Longitude & $\begin{array}{c}\text { Elevatio } \\
\text { n(a.s.l.) }\end{array}$ \\
$27^{\circ} 36^{\prime} 45.7^{\prime \prime} \mathrm{N}$ & $85^{\circ} 5^{\prime} 32^{\prime \prime} \mathrm{E}$ & $2174 \mathrm{~m}$ & $28^{\circ} 23^{\prime} 21.9^{\prime \prime} \mathrm{N}$ & $83^{\circ} 42^{\prime} 22.1^{\prime \prime} \mathrm{E}$ & $2675 \mathrm{~m}$ \\
$27^{\circ} 36^{\prime} 44.7^{\prime \prime} \mathrm{N}$ & $85^{\circ} 5^{\prime} 37.6^{\prime \prime} \mathrm{E}$ & $2274 \mathrm{~m}$ & $28^{\circ} 23^{\prime} 42.2^{\prime \prime} \mathrm{N}$ & $83^{\circ} 42^{\prime} 9.2^{\prime \prime} \mathrm{E}$ & $2770 \mathrm{~m}$ \\
$27^{\circ} 36^{\prime} 2.1^{\prime \prime} \mathrm{N}$ & $85^{\circ} 5^{\prime} 13.4^{\prime \prime} \mathrm{E}$ & $2374 \mathrm{~m}$ & $28^{\circ} 24^{\prime} 4.9^{\prime \prime} \mathrm{N}$ & $83^{\circ} 41^{\prime} 58.9^{\prime \prime} \mathrm{E}$ & $2874 \mathrm{~m}$ \\
$27^{\circ} 35^{\prime} 37.1^{\prime \prime} \mathrm{N}$ & $85^{\circ} 5^{\prime} 57.3^{\prime \prime} \mathrm{E}$ & $2474 \mathrm{~m}$ & $28^{\circ} 24^{\prime} 5.2^{\prime \prime} \mathrm{N}$ & $83^{\circ} 41^{\prime} 46.8^{\prime \prime} \mathrm{E}$ & $2968 \mathrm{~m}$ \\
$27^{\circ} 35^{\prime} 37.4^{\prime \prime} \mathrm{N}$ & $85^{\circ} 5^{\prime} 17.3^{\prime \prime} \mathrm{E}$ & $2574 \mathrm{~m}$ & $28^{\circ} 24^{\prime} 0.9^{\prime \prime} \mathrm{N}$ & $83^{\circ} 41^{\prime} 34.7^{\prime \prime} \mathrm{E}$ & $3079 \mathrm{~m}$ \\
\hline
\end{tabular}

5

6

7

8

9

10

11

12

13 


\section{Table 2 (on next page)}

Table 2

Results of regression analysis between various traits of $R$. alpina and elevation. SLA = Specific Leaf Area. 
1 Table 2: Results of regression analysis between various traits of $R$. alpina and elevation. SLA = 2 Specific Leaf Area.

3

\begin{tabular}{|c|c|c|c|c|c|c|c|}
\hline \multicolumn{8}{|c|}{ Coefficients and $95 \%$ Cis } \\
\hline Traits & Parameters & 2.5 & 50 & 97.5 & Distribution & link & $\mathrm{P}$ \\
\hline \multirow{2}{*}{$\begin{array}{l}\text { Plant } \\
\text { height }\end{array}$} & $\mathrm{m}$ & $3.85 \mathrm{E}-05$ & $6.48 \mathrm{E}-05$ & $9.12 \mathrm{E}-05$ & Gamma & Inverse & \\
\hline & $\mathrm{b}$ & $-1.52 \mathrm{E}-01$ & $-7.71 \mathrm{E}-02$ & $-1.85 \mathrm{E}-05$ & & & 0.017 \\
\hline \multirow{2}{*}{$\begin{array}{l}\text { Leaf } \\
\text { length }\end{array}$} & $\mathrm{m}$ & $6.99 \mathrm{E}-05$ & $8.37 \mathrm{E}-05$ & $9.75 \mathrm{E}-05$ & Gamma & Inverse & \\
\hline & $\mathrm{b}$ & $-1.87 \mathrm{E}-01$ & $-1.47 \mathrm{E}-01$ & $-1.08 \mathrm{E}-01$ & & & $<0.001$ \\
\hline \multirow[t]{2}{*}{ Leaf area } & $\mathrm{m}$ & $-4.00 \mathrm{E}-02$ & $-3.60 \mathrm{E}-02$ & $-3.30 \mathrm{E}-02$ & Gamma & Identity & \\
\hline & $\mathrm{b}$ & $1.09 \mathrm{E}+02$ & $1.21 \mathrm{E}+02$ & $1.33 \mathrm{E}+02$ & & & $<0.001$ \\
\hline \multirow[t]{2}{*}{ SLA } & $\mathrm{m}$ & 3.91E-07 & $3.33 \mathrm{E}-06$ & $6.31 \mathrm{E}-06$ & Gamma & Inverse & \\
\hline & $\mathrm{b}$ & $-1.43 \mathrm{E}-02$ & $-5.85 \mathrm{E}-03$ & $2.55 \mathrm{E}-03$ & & & 0.114 \\
\hline Stomata & $\mathrm{m}$ & $9.10 \mathrm{E}-02$ & $1.24 \mathrm{E}-01$ & $1.58 \mathrm{E}-01$ & Gaussian & Identity & \\
\hline Density & $\mathrm{b}$ & $-2.75 \mathrm{E}+02$ & $-1.78 \mathrm{E}+02$ & $-8.15 E+01$ & & & 0.005 \\
\hline
\end{tabular}

4

5

6 


\section{Table 3 (on next page)}

Table 3

Results of regression analysis between various traits of $R$. purpurea and elevation. SLA = Specific Leaf Area. 
1 Table 3: Results of regression analysis between various traits of $R$. purpurea and elevation. SLA 2 = Specific Leaf Area.

3

\begin{tabular}{llrrrrrr}
\hline & & \multicolumn{7}{c}{ Coefficients and 95 \% Cis } & & & \\
Traits & Parameters & 2.5 & 50 & 97.5 & Distribution & link & P \\
& & & & & & & \\
\hline Plant & $\mathrm{m}$ & $-7.90 \mathrm{E}-03$ & $-5.00 \mathrm{E}-03$ & $-2.10 \mathrm{E}-03$ & Gaussian & Identity & 0.044 \\
height & $\mathrm{b}$ & $2.59 \mathrm{E}+01$ & $3.29 \mathrm{E}+01$ & $3.99 \mathrm{E}+01$ & & & \\
Leaf & $\mathrm{m}$ & $-7.00 \mathrm{E}-03$ & $-2.00 \mathrm{E}-03$ & $3.00 \mathrm{E}-03$ & Gamma & Identity & 0.47 \\
length & $\mathrm{b}$ & $1.15 \mathrm{E}+01$ & $2.32 \mathrm{E}+01$ & $3.49 \mathrm{E}+01$ & & & \\
Leaf area & $\mathrm{m}$ & $-6.70 \mathrm{E}-02$ & $-5.80 \mathrm{E}-02$ & $1.55 \mathrm{E}+02$ & Gamma & Identity & $<\mathbf{0 . 0 0 1}$ \\
& $\mathrm{b}$ & $-4.80 \mathrm{E}-02$ & $1.79 \mathrm{E}+02$ & $2.03 \mathrm{E}+02$ & & & \\
SLA & $\mathrm{m}$ & $-7.55 \mathrm{E}-06$ & $-1.90 \mathrm{E}-06$ & $3.71 \mathrm{E}-06$ & Gamma & Inverse & 0.55 \\
& $\mathrm{~b}$ & $-4.40 \mathrm{E}-03$ & $8.91 \mathrm{E}-03$ & $2.26 \mathrm{E}-02$ & & & \\
Stomata & $\mathrm{m}$ & $-7.31 \mathrm{E}-02$ & $-6.18 \mathrm{E}-06$ & $-5.05 \mathrm{E}-06$ & Gamma & Inverse & 0.002 \\
Density & $\mathrm{b}$ & $2.04 \mathrm{E}-02$ & $2.32 \mathrm{E}-02$ & $2.59 \mathrm{E}-02$ & & & \\
\hline
\end{tabular}

4

5

6

7 